\title{
LIBERDADE DE EXPRESSÃO E DEMOCRATIZAÇÃO NO NOVO CONSTITUCIONALISMO LATINO-AMERICANO: O CASO DAS RÁDIOS COMUNITÁRIAS NA LEI DE MEIOS DO EQUADOR
}

\author{
FREEDOM OF SPEECH AND DEMOCRATIZATION IN THE NEW LATIN \\ AMERICAN CONSTITUCIONALISM: THE COMMUNITARY RADIOS IN \\ ECUADOR'S MEDIA LAW
}

\author{
${ }^{1}$ Marta Thais Leite dos Santos \\ ${ }^{2}$ Tereza Margarida Costa de Figueiredo
}

\begin{abstract}
RESUMO
O presente artigo, através de pesquisa bibliográfica e documental, faz um estudo de caso da nova Lei de Meios do Equador, no contexto do novo constitucionalismo latino-americano, a partir da finalidade concernente às rádios comunitárias, ou seja, meios de comunicação populares para promoção da cidadania e mobilização social. A democratização dos meios de comunicação também perpassa a concretização da liberdade de expressão como um direito de participação.
\end{abstract}

Palavras-chave: Novo constitucionalismo latino-americano. Rádios comunitárias. Lei de Meios do Equador. Democracia Participativa. Comunicação Comunitária.

\begin{abstract}
This article, through bibliographic and documental research, studies the new law of Media in Equator, in the context of the new latin american constitucionalism, into the perspective of community radios, zas popular communication media which promote citizenship and social mobilization. The communication media democratization also goes through the concretization of the freedom of expression as a participation right.
\end{abstract}

Keywords: New latin american constitucionalism. Communitary radio. Equator's law of media. Participative Democracy. Communitary Communication.

\footnotetext{
${ }^{1}$ Mestranda em Direito pela Universidade Católica de Pernambuco - UNICAP, Recife, Pernambuco, (Brasil). Email: marta thais@hotmail.com

${ }^{2}$ Mestre em Direito Constitucional pela Universidade Federal do Rio Grande do Norte - UFRN, Natal, (Brasil). Advogada E-mail: terezaa.figueiredo@yahoo.com.br
} 


\section{INTRODUÇÃO}

As rádios comunitárias bem como outros veículos de produção independente começaram a surgir a partir de um movimento em prol da democratização dos meios. Esses movimentos populares ansiavam sobretudo o reconhecimento legal dessas experiências; como garantir acesso a modos de comunicação baratos em que pudessem aumentar o trabalho de conscientização política e enfatizar a luta por direitos e cidadania a partir do local.

Há correntes que pensam as rádios comunitárias como forma de concorrer com emissoras comerciais, mas há também aquelas que enfatizam o poder de propagar educação cidadã por entre as comunidades: conteúdo que é produzido pelos próprios moradores/beneficiados, que conhecem e vivenciam a realidade específica de onde habitam. É sob esta última ótica que focaremos o nosso trabalho.

Através da rádio comunitária pode ser construído um espaço democrático para difusão de ideias em uma comunidade. Além de fortalecer o conceito de cidadania e participação, com a reformulação de seus conteúdos, poderão ser produzidos espaços para a mobilização social. A rádio comunitária aparece como um espaço de educação não formal, próximo à comunidade em suas tradições, manifestações culturais e hábitos sociais.

Com este embasamento, justificamos o presente estudo ao abordar o papel das rádios comunitárias no novo constitucionalismo latino-americano para construção da cidadania e mobilização social a partir do estudo de caso do Equador. Tal país, através da recém-aprovada Lei de Meios, que regula o capítulo da Comunicação Social da sua recente Constituição Federal - datada de 2008 -, determina em sua legislação que 34\% dos espectros do rádio de seu território deverão pertencer a rádios comunitárias.

$\mathrm{Na}$ Constituição promulgada em 2008 foi definido que os bancos não poderiam ser acionistas de empresas de comunicação, bem como foi estipulado prazo máximo de 365 dias para o Legislativo aprovar uma nova Lei de Meios. Contudo, isso não foi respeitado, posto que tal Lei veio a entrar em vigor apenas em 2013, substituindo a Lei de Radiodifusão anteriormente vigente, elaborada durante a ditadura militar.

Por que, então, se desejava manter uma Lei de Radiodifusão que não mais conseguia regular, com efetividade, a realidade dos meios de comunicação do Equador? Em respeito à liberdade de expressão e à propriedade privada, como alegaram os empresários locais? Ou em respeito aos interesses de um seleto grupo detentor de $90 \%$ do espectro equatoriano?

Democratizar a comunicação a partir da redistribuição dos meios é fomentar nas 
minorias o desejo de influir de forma direta nas decisões do país. Para isso, a Constituição do Equador garantiu, além da redistribuição, a implantação de políticas públicas de incentivo para a produção de conteúdo pelos setores minoritários, de modo que se estabeleceu uma democracia participativa. Isto porque só se pode falar em liberdade de expressão quando se expressa, bem como se tem consciência do que se expressa. O Equador, apesar de ainda ter um longo caminho na concretização dos efeitos desta lei, coloca-se um passo à frente no reconhecimento e respeito a uma sociedade plural.

Vale ressaltar que o trabalho é feito por meio de uma pesquisa qualitativa, de cunho teórico, através de levantamento bibliográfico e análise documental.

\section{RÁDIOS COMUNITÁRIAS: MOBILIZAÇÃO SOCIAL E CIDADANIA PARA FORTALECIMENTO DO LOCAL}

A comunicação comunitária, também chamada de popular ou alternativa, nasce a partir da necessidade do fazer comunicacional que abrolha dos grupos populares. A mídia seria construída do povo para o povo, objetivando suscitar reflexões acerca de sua realidade. Para Gilberto Gimenez (1979, p. 70), ela "implica a quebra da lógica da dominação e se dá não a partir de cima, mas a partir do povo, compartilhando dentro do possível seus próprios códigos".

Rádio comunitária pode ser entendida como aquela realmente voltada e identificada como tal, na qual se reconhece facilmente o trabalho desenvolvido para uma determinada comunidade. De acordo com Cecilia Peruzzo (2007, p. 69),

a rádio comunitária que faz jus a este nome é facilmente reconhecida pelo trabalho que desenvolve. Ou seja, transmite uma programação de interesse social vinculada à realidade local, não tem fins lucrativos, contribui para ampliar a cidadania, democratizar a informação, melhorar a educação informal e o nível cultural dos receptores sobre temas diretamente relacionados às suas vidas.

O rádio como veículo de comunicação ainda pode ser considerado,

modernizado, refeito, revigorado; ele já não é aquele de Getúlio Vargas nem é o palanque sonoro da 'identidade nacional'; é mais variável, diverso, multifacetado, fragmentado... E imprescindível. Um pouco distante de ser um congregador nacional, assume com força e propriedade o de 'agregador local, um porta-voz da cidade, um agente comunitário’ (BUCCI, 2004, p. 8).

O conteúdo que é produzido pela rádio comunitária volta-se para a comunidade em questão, ou seja, é feito pelos moradores para os moradores, funcionando como um caminho de 
discussão para a comunidade. E, com isso, nada tem a ver com rádios que veiculam músicas ditas populares ou de clamor popular e que apresentam um material com teor questionável.

Rádios comunitárias vão indicar a democratização dos meios de comunicação, através da participação coletiva no processo comunicacional. Por conseguinte, surge uma nova forma de interpretação da mídia, entendida como instrumento de efetivação da cidadania, inclusão e mobilização social e disseminação de novas propostas. Contudo, uma das grandes críticas às rádios comunitárias é quanto à deturpação de seus fins. Há casos em que tais veículos servem como fins eleitoreiros ou para barganhar ajudas/benefícios políticos.

$\mathrm{Na}$ redistribuição do poder sobre o que é veiculado nos meios de comunicação é que deve ser pensada a importância da comunicação comunitária enquanto força de expressão dos segmentos, por menores que sejam, na sociedade como um todo. O pluralismo de um Estado Democrático de Direito resguarda não só os direitos e garantias das maiorias, mas também os das minorias, sendo, inclusive, um dos objetivos da República Federativa Brasileira, a construção de uma sociedade livre, justa e solidária, consoante disposto no art $3^{\circ}$, I, CF.

Todavia, para que uma sociedade plural seja livre, justa e solidária, deve ser assegurado espaço a todos para se manifestarem, de forma paritária. Somente a partir da veiculação diversificada de conteúdo nos meios de comunicação é que o sujeito consegue identificar-se com este, posto que este conteúdo será pensado por ele e para ele e seus iguais, e não por segmentos também minoritários (mas aqui em número, sendo majoritários em poder) que visam essencialmente a massificação da informação, fazendo com que ela atenda única e exclusivamente aos seus interesses.

\begin{abstract}
As rádios comunitárias refletem movimentações da sociedade civil, na medida em que representam um canal de contestação contra o sistema de radiodifusão vigente e que impede o acesso às ondas sonoras da maior parte da sociedade. Em sua programação divulgam sua movimentação como agrupamento, com necessidades, características, culturas e demandas próprias. A mídia comunitária volta-se para assuntos de interesse das comunidades, já que a realidade, bem como as demandas, os desafios e as potencialidades dessas nem sempre encontram ressonância na mídia convencional. Dessa forma, a mídia comunitária mantém-se aberta à participação da comunidade em todo o processo de criação, produção e divulgação da mensagem, assim como na gestão da própria mídia, entre outras características (BAHIA, 2008, p. 72-73).
\end{abstract}

A integração do indivíduo a partir do local faz com o elo fundador da cidadania seja estabelecido de forma mais concreta, mais sólida. Para que, se construa o espaço local, primeiro deve haver redistribuição dos meios de comunicação já existentes, para assim, posteriormente, através do fortalecimento dos meios de comunicação comunitários, a exemplo das rádios, como aqui analisamos, estas serão mais um instrumento de mobilização social e cidadania. Vale 
ressaltar que não estamos falando apenas de um processo de democratização que atinge apenas os veículos comunicacionais, mas a própria estrutura do Estado de Democrático Direito.

\section{OPINIÃO PÚBLICA, DEMOCRATIZAÇÃO DOS MEIOS DE COMUNICAÇÃO E CRISE NA DEMOCRACIA}

A “opinião pública”, ao contrário do que a nomenclatura leva a pensar, não retrata necessariamente o que pensa a maioria do povo, mas sim o que aqueles que detêm acesso aos meios de comunicação pensam e querem que seja pensado pelos demais. Dessa forma, o processo comunicacional resta incompleto, superficial, posto que não há troca real de informações, mas sim veiculação dos mesmos conteúdos, sem chance de o espectador reagir, rebater ou acrescentar.

Democratização dos meios de comunicação, tema tão abordado na atualidade, não se reduz a instalar pontos de acesso à rede sem fio gratuitos em determinados locais da cidade, baratear o custo dos aparelhos televisivos, aumentar a programação "aberta" ou melhorar o sinal do espectro desta. Democratizar a comunicação é muito mais do que garantir ao indivíduo o direito de expressar-se de forma livre, abstendo-se o Estado de censurá-lo, mas, principalmente, é fornecer mecanismos para que aquele indivíduo tenha condições de desenvolver conteúdo a ser veiculado e não fique a mercê do que setores minoritários da sociedade, que detém o controle dos meios de comunicação, veiculam e acham que é apropriado para ele.

Não se pode mais pensar em comunicação como um fenômeno estático, onde um indivíduo informa e o outro se encontra pronto a receber. Em uma sociedade plural, tal qual esta que nos encontramos, as vozes da minoria também se devem fazer presentes. Em um processo dialógico comunicacional as duas partes devem encontrar-se em interação: informando e sendo informadas, trocando experiências em um mesmo fluxo de conteúdo.

\footnotetext{
As emissoras comunitárias trabalham (no sentido de divulgar, abrir discussões) não só os direitos de terceira e quarta geração, mas também os de primeira e segunda, que tratam dos direitos civis e sociais, abrindo debates e espaços para a participação das minorias, que manifestam desejo e lutam para opinar sobre questões coletivas e desempenharem, assim, seu papel de cidadãos. Acredita-se que, dessa forma, tais emissoras contribuirão a estender a consciência de cidadania de sujeitos individuais e coletivos na sociedade contemporânea.

Nessa perspectiva, o engajamento do indivíduo na produção e na circulação de mensagens é fundamental, já que, pela participação, os receptores, que, até terem acesso à produção e emissão de mensagens, eram passivos, tornam-se também emissores do processo de comunicação. Tal situação aqui é considerada a partir dos
} 
meios de comunicação populares ou alternativos (BAHIA, 2008, p. 95).

Mas como isso é possível em um Estado no qual, apesar de se denominar Democrático de Direito, há concentração dos veículos de comunicação e, consequentemente, monopolização do seu conteúdo? Será que realmente podemos nos considerar abarcados pelo fenômeno da democratização da comunicação quando para algumas pessoas o acesso à internet em sua casa ainda é uma realidade distante? Ou ainda, será que basta universalizar o acesso à rede, baratear as televisões e considerar como incluídos e atuantes no processo comunicacional aqueles que têm um aparelho de rádio e, consequentemente, estaremos diante de uma comunicação democrática? Não, o problema é bem mais denso.

Além da imprescindibilidade de facilitar o acesso da população aos veículos comunicacionais, deve ser garantida a esta o controle de seu conteúdo, do que será veiculado. O povo deve sentir-se representado, e aqui não podemos pensar em povo como um conceito homogêneo, posto que, consoante Neves (2012), um Estado Democrático de Direito não busca homogeneizar a sociedade, tampouco evitar as pluralidades, elementos intrínsecos de sua formação, cabendo a ele apenas propiciar o consenso dos procedimentos para que os dissensos de conteúdos possam conviver harmoniosamente em seu núcleo. A igualdade, assim, aceita a diferença em seu cerne.

Para que haja identidade entre o indivíduo e o conteúdo veiculado, este deve lhe pertencer, deve ter sua participação direta. Assim, todos os segmentos da sociedade devem ter controle sobre o que é veiculado para si, pois apenas quando este for detentor do poder-dever de ser inserido no processo comunicacional não mais como mero espectador, mas como sujeito disposto a contribuir a partir de sua realidade, é que tomará seu quinhão na responsabilidade sobre o Estado e tudo que isto implica, em uma efetiva concretização do que seria cidadania. Portanto, não se deve falar em mera democratização dos meios, mas sim em democratização dos conteúdos, tal qual concerne à comunicação comunitária.

Para Bonavides (2001), só se pode pensar em Estado Social Democrático de Direito quando estivermos diante de uma democracia participativa, sendo esta composta em maior parte pela representação direta do povo e em menor parte pela democracia representativa. Isso por que, diante da crise da atual democracia percebe-se que o povo, elemento formador do Estado, não se sente representado, não sente que seus interesses são defendidos genuinamente e, por conseguinte, não se identifica com o Estado do qual faz parte enquanto elemento intrínseco. Como resultado, temos uma cidadania superficial, exercida por uma população apática, que não toma para si as responsabilidades do destino do Estado porque não se sente vinculada a este, 
não enxerga nele tutela e garantia de seus direitos de forma efetiva.

A partir de uma democracia participativa, que apesar de não excluir a forma representativa, aumenta consideravelmente a atividade do povo enquanto nação, através de maior número de instrumentos que convoquem os indivíduos a opinarem no destino da nação, é que alcançaremos o verdadeiro Estado Social Democrático de Direito. Nas lições de Bonavides (idem, p. 47),

(...) A mídia, nas mãos da classe dominante, é a mais irresistível força de sustentação do status quo e de seus governos conservadores, impopulares, injustos e reacionários. Afastá-la daquelas mãos, democratizá-la, protegê-la, mediante dispositivos constitucionais que lhe assegurem a legitimidade no exercício de suas funções e deveres sociais, é o primeiro dos pressupostos da democracia participativa. Em verdade, valendo-se da mídia domesticada, da mídia submissa, da mídia estipendiada, o Poder Executivo corrompe a democracia representativa, e corrompera, com muito mais intensidade e desfaçatez, a democracia participativa e seus mecanismos plebiscitários.

O Estado Social Democrático de Direito a ser alcançado não é aquele que irradia normas de natureza programática, de muito conteúdo e pouca eficácia, mas um Estado Social Democrático que preze pela participação do indivíduo em todas as suas esferas, através do aumento das ações de iniciativas populares, dos plebiscitos e referendos. Democratizar os meios de comunicação promoverá uma ruptura naquilo que chamamos de opinião pública, bem como é uma forma de efetivar a democracia como direito humano.

\section{O NOVO CONSTITUCIONALISMO LATINO-AMERICANO E A CONSTITUIÇÃO EQUATORIANA DE 2008}

Quando se fala no constitucionalismo da América Latina deve-se atentar para os novos contornos que este vem tomando. Prezando pela integração das minorias à sociedade, conferindo a estas espaço para efetiva participação, vivemos um momento de redefinição do conceito de democracia e, por conseguinte, das estruturas do Estado Social Democrático de Direito, posto que estes são institutos indissociáveis.

En el nuevo constitucionalismo latinoamericano se partió del supuesto de que sólo hay una manera de equilibrar la capacidad de penetración fáctica de los grupos de poder económicos: dar poder institucional a la ciudadanía. Que la ciudadanía tenga capacidad individual y coletiva interactuar com los ámbitos de toma de decisiones. Dos son los espacios de participacíon fundamentales: a) control de los órganos de gobierno; b) toma de decisiones (ROMEO, 2014, p. 175). 
Assim, prezam-se pela majoração da participação direta, conferindo importância maior aos direitos de solidariedade, que exigem atuação concomitante entre o Estado, os indivíduos e a sociedade como um todo, sendo um dos objetivos expressos na Constituição do Equador, o fortalecimento da unidade nacional pautada pela diversidade (art. 3, 3).

Dentre as mais diversas mudanças ocorridas com vistas a garantir uma participação popular significativa está à necessidade e urgência de se democratizar os meios de comunicação. Nesse âmbito, impende destacar as mudanças no constitucionalismo equatoriano, bem como a nova Lei de Meios em vigor desde 2013.

Em 28 de setembro de 2008, esse país promulgou, através de reforma constitucional, uma nova Constituição, esta contando com mais de $64 \%$ da aprovação popular, através de referendo, em sessões constituintes espalhadas por todo o país. O novo documento diferenciase dos mais pela presença da democracia participativa em todo o seu conteúdo, conferindo ao meio ambiente titularidade de direitos, desviando, assim, o centro do ordenamento constitucional do homem para o biocentrismo, do qual todos os indivíduos fazem parte de forma igual e, portanto, tornam-se responsáveis pelo cumprimento e exigibilidade dos direitos da natureza. A nova Carta Magna equatoriana assegurava também a participação de segmentos marginalizados que, apesar de fazerem parte da história do país, nunca foram previstos ou tampouco tutelados em um texto constitucional, a exemplo dos indígenas e dos afrodescendentes.

De acordo com Brandão (2013), diversas são as denominações adotadas para esse novo fenômeno na América Latina, como Novo Constitucionalismo Latino-Americano (Viciano e Dalmau), Constitucionalismo Mestiço (Baldi), Constitucionalismo Andino e Constitucionalismo Pluralista Intercultural (Wolkmer), Neoconstitucionalismo Transformador (Santamaría), Constitucionalismo Pluralista (Fajardo), Constitucionalismo Experimental ou Constitucionalismo Transformador (Sousa Santos), Constitucionalismo da Diversidade (Uprimmy), etc. Observa Brandão (2013, p. 35), que “[...] no plano latino-americano; existe um Novo Constitucionalismo Pluralista que se contrapõe ao antigo Constitucionalismo latinoamericano, marcado pelo elitismo, pela ausência de participação popular e pela subordinação das práticas, saberes e conhecimento dos povos indígenas”.

Por conseguinte, segundo Wolkmer (2010, p. 153),

O terceiro ciclo do novo constitucionalismo latino-americano passa a ser representado pelas recentes e vanguardistas Constituições do Equador (2008) e da Bolívia (2009); para alguns publicistas, tais textos políticos expressariam um constitucionalismo plurinacional comunitário, identificado com um outro paradigma não universal e 
único de Estado de Direito, coexistente com experiências de sociedades interculturais (indígenas, comunais, urbanas e camponesas) e com práticas de pluralismo igualitário jurisdicional (convivência de instâncias legais diversas em igual hierarquia: jurisdição ordinária estatal e jurisdição indígena/camponesa).

Fajardo (2010) distingue, no que denomina constitucionalismo pluralista, três ciclos distintos de "reformas constitucionais que buscam reconfigurar o modelo de Estado e a relação entre o Estado e os povos indígenas". É o Constitucionalismo multicultural (1982-1988), o Constitucionalismo pluricultural (1989-2005) e o Constitucionalismo plurinacional (20062009). No que interessa ao trabalho, o qual se encaixa a Constituição equatoriana de 2009 e a Boliviana de 2008, o ciclo do Constitucionalismo plurinacional (2006-2009) desenvolve-se no contexto da aprovação da Declaração das Nações Unidas sobre os Direitos dos Povos Indígenas (2007).

De acordo com Fajardo (idem, p. 141), "tales reformas constitucionales expresan antiguas y nuevas demandas indígenas pero también la resistencia de antiguos y nuevos colonialismos", no qual sua principal característica é a proposta de "refundação do Estado", com reconhecimento explícito das raízes milenares dos povos que, por consequência, possibilitou a emergência da figura do Estado Plurinacional. Observa-se também como principal característica e inovação o reconhecimento de novos direitos sociais que incorporam a visão indígena, como o direito ao bem-viver.

Ainda segundo Fajardo (2010, p. 155-157), são bases para o reconhecimento deste novo constitucionalismo plurinacional: 1) Estado plurinacional; 2) reconocimiento de la existencia precolonial de naciones/pueblos indígenas y de su libre determinación; 3) responsabilidad social del Estado; 4) nuevos derechos de individuos, grupos, comunidades, pueblos, naciones y nacionalidades indígenas; 5) nuevos derechos sociales (al agua, "al buen vivir", a la seguridad alimentaria); 6) derechos de la naturaleza del Ecuador; autonomías indígenas; 7) instituciones mixtas plurinacionales interculturales; 8) se reconoce la jurisdicción indígena de modo explícito.

No entender de Bragato (2015, p. 54), os textos das Constituições equatoriana e boliviana, representantes do terceiro ciclo no novo constitucionalismo ao qual se refere Fajardo (2010), trazem as inovações substanciais ao novo constitucionalismo latino-americano. Quanto ao conteúdo das normas, ambas as Constituições trazem disposições inéditas, sem prejuízo dos clásicos direitos civis e políticos característicos do antigo constitucionalismo existente na América Latina. 
respectivo. Estes direitos abrangem: educação, água, moradia, alimentação, cultura e ciência, informação e comunicação, meio-ambiente, trabalho e segurança social. Consagra também disposições especiais sobre indivíduos e grupos vulneráveis: Adultas e adultos maiores (idosos), jovens, mobilidade humana, mulheres grávidas, crianças e adolescentes, pessoas portadoras de deficiencia, pessoas com enfermedades catastróficas, pessoas privadas de liberdade, pessoas usuárias e consumidoras. Garante à comunidade, povos e nacionalidades uma série de vinte e um direitos coletivos. E à natureza, chamada de Pacha Mama, reconhece a condição de sujeito de direitos e garante o direito à sua existencia e à mantença e regeneração de seus ciclos vitais, estrutura, função e procesos evolutivos. Ademais, prevê o direito à sua restauração, independente de indenização a quem tenham direito as pessoas que dependam dos sistemas naturais afetados (BRAGRATO, idem, p. 54-55).

A Constituição do Equador pauta-se nos direitos do pacha mama e oficializa a proposta do Sumák Kawsay ou Buen Vivir como o princípio filosófico que pauta as ações do governo, sendo uma proposta de convivência solidária entre as mais diversas culturas coexistentes, onde é garantido a estas o poder de contribuir com sua cultura, seu saber, para o desenvolvimento de um Estado pautado no bem estar social - este diferente da concepção clássica de Welfare State, não existindo a utilização de normas programáticas, mas sim uma busca pela efetividade dos direitos de fraternidade através da democracia participativa, da participação direta de todos os setores sociais.

Bragato e Castilho (2014, p. 12), contextualizam o tema e, ao citar Santamaría (2011) ressaltam que,

Este novo constitucionalismo ostenta características descolonizadoras, com reconhecimento da cosmovisão indígena e com um novo projeto societário, que busca incluir sujeitos e coletivos historicamente excluídos e marginalizados, especialmente os indígenas, as mulheres e os campesinos. Nesse sentido, Santamaría (2011, p. 75 77) considera o que denominou Neoconstitucionalismo Andino ou Transformador, como uma mudança importante em relação ao modelo constitucional de base europeia até então adotado na América Latina. Segundo o autor, a necessidade de se adotarem novos modelos decorre da inadequação do constitucionalismo europeu para lidar com problemas próprios da América Latina e com os quais a Europa não conviveu, a saber: a existência do período colonial, de um estado de segregação e exclusão de populações originárias e majoritárias (que tem relação direta com a pobreza generalizada) e a não implementação das conquistas dos movimentos emancipatórios europeus em nossa região.

Destarte, o Estado equatoriano assume uma identidade plurinacional, abarcando e tutelando os mais diversos segmentos presentes na sociedade, desde os indígenas e afrodescendentes, na busca do combate às desigualdades sociais, através de uma série de novos direitos coletivos, perpassando, também, pelo crescimento econômico dissociado da exploração predatória à natureza, e, por fim, pela participação popular no redimensionamento das estruturas democráticas. 


\title{
4. LEI DE MEIOS DO EQUADOR: A LIBERDADE DE EXPRESSÃO COMO PRESTAÇÃO POSITIVA DO ESTADO
}

Na nova Constituição equatoriana, promulgada em 2008, foi definido que os bancos não poderiam ser acionistas de empresas de comunicação, bem como foi estipulado prazo máximo de 365 dias para o Legislativo aprovar uma nova Lei de Meios, decisão que foi taxada de restritiva à liberdade de expressão e à propriedade privada pelos grandes empresários. Contudo, o prazo não foi respeitado, posto que tal Lei veio a entrar em vigor apenas em 2013, substituindo a Lei de Radiodifusão anteriormente vigente, elaborada durante a ditadura militar.

O art. 384 da Constituição equatoriana define o sistema de comunicação social do país, bem como consagra a Lei de Meios supracitada, que veio a ser editada posteriormente.

\begin{abstract}
Comunicación social: Art. 384 - El sistema de comunicación social asegurará el ejercicio de los derechos de la comunicación, la información y la libertad de expresión, y fortalecerá la participación ciudadana. El sistema se conformará por las instituciones y actores de carácter público, las políticas y la normativa; y los actores privados, ciudadanos y comunitarios que se integren voluntariamente a el. El Estado formulará la política pública de comunicación, con respeto irrestricto de la libertad de expresión y de los derechos de la comunicación consagrados en la Constitución y los instrumentos internacionales de derechos humanos. La ley definirá su organización, funcionamiento y las formas de participación ciudadana" (EQUADOR, 2008).
\end{abstract}

A recém-aprovada Lei de Meios, que regula o capítulo da Comunicação Social da Constituição Federal, determina em sua legislação que 34\% dos espectros do rádio de seu território deverão pertencer a rádios comunitárias, parcela sensivelmente maior que a destinada aos setores público, privado e estatal. Além da redistribuição, a lei prevê ainda a criação de políticas públicas de incentivo às rádios comunitárias, de modo que estas tenham subsídios suficientes para a produção de seu conteúdo.

Os meios de comunicação comunitários são definidos, de acordo com a Lei de Meios do Equador, também chamada Ley orgánica de comunicación (2014), desta forma:

Definición.- Los medios de comunicación comunitarios son aquellos cuya propiedad,
administración y dirección corresponden a comunas, comunidades, pueblos,
nacionalidades, colectivos u organizaciones sociales. No tienen fines de lucro y su
rentabilidad es social. Los medios de comunicación comunitarios no podrán ser
sometidos a limitaciones de definición y distribución de contenidos, de cobertura
geográfica ni a controles especiales o cualquier otra forma de discriminación que les
impida operar en igualdad de condiciones que los demás medios de comunicación.

O que se vê, portanto, na democratização dos meios e mais especificamente na Lei de Meios do Equador, não é uma restrição à liberdade de expressão, tampouco o desrespeito à propriedade privada, mas sim uma concretização de ambos. A liberdade de expressão, 
diferentemente do que coloca Gilmar Mendes e Branco(2009), implica em fornecimento, por parte do Estado, de mecanismos que propiciem ao indivíduo de fato expressar-se - ou não fazêlo, de modo livre, consciente, não apenas através da garantia do direito de resposta, como o autor coloca.

"O ser humano se forma no contato com o seu semelhante, mostrando-se a liberdade de se comunicar como condição relevante para a própria higidez psicossocial da pessoa. O direito de se comunicar livremente conecta-se com a característica da sociabilidade, essencial ao ser humano" (MENDES; BRANCO, 2009, p. 403). Segundo Machado (2002, 416), o direito à liberdade de expressão constitui direito mãe a partir do qual as demais liberdades comunicativas foram sendo autonomizadas, tendo em vista responder às sucessivas mudanças tecnológicas, econômicas e estruturais relevantes no domínio da comunicação.

Não se pode, em um Estado Democrático de Direito, pensar no direito à liberdade de expressão como apenas um dever de abstenção do Estado, sem que enseje nenhuma contraprestação deste, posto que em uma sociedade plural e, por conseguinte, desigual, nem todos terão a mesma "liberdade" para veicular seus pensamentos, suas ideias, cabendo ao Estado fornecer mecanismos para o nivelamento destas diferenças, sob pena de estar cerceando um direito fundamental do indivíduo.

A liberdade de expressão, portanto, na contemporaneidade, deve ser interpretada à luz do princípio da igualdade material e da não discriminação, de modo a assumir, para o Estado, o caráter de acesso, participação (HESSE, 2009), isto porque não mais se pode pensar que igualdade e liberdade são valores em disputa, em antítese. No Estado Democrático de Direito, em seu viés Social de democracia participativa, liberdade e igualdade são valores complementares: não se pode ser livre sem que se parta do mesmo patamar. Assim, a igualdade liberta, pois propicia ao indivíduo que fique à vontade para veicular seu pensamento, em um verdadeiro exercício da cidadania.

\footnotetext{
Nessa condição e a democracia do Estado social, por conseguinte, o mais fundamental dos direitos da nova ordem normativa que se assenta sobre a concretude do binômio igualdade-liberdade; ordem cujos contornos se definem já com desejada nitidez e objetividade, marcando qualitativamente um passo avante na configuração dos direitos humanos. (BONAVIDES, 2001, p. 160)
}

Quanto à questão da propriedade privada, esta deve, acima de tudo, cumprir sua função social. No momento em que temos uma forte concentração dos meios de comunicação em setores que, de fato, não representam o povo em seu sentido de maioria composta por minorias, há desvirtuamento do que seria a função destes, qual seja a de informar livre e 
democraticamente, possibilitando a todos igual oportunidade de acesso e de veiculação, troca de conteúdos e opiniões.

A questão é por que, então, se desejava manter uma Lei de Radiodifusão que não mais conseguia regular, com efetividade, a realidade dos meios de comunicação do Equador? Em respeito à liberdade de expressão e à propriedade privada, como alegaram os empresários locais? Ou em respeito aos interesses de um seleto grupo detentor de $90 \%$ do espectro equatorial?

Democratizar a comunicação a partir da redistribuição dos meios é fomentar nas minorias o desejo de influir de forma direta nas decisões do país. O Equador, apesar de ainda ter um longo caminho na concretização dos efeitos desta lei, coloca-se um passo à frente no reconhecimento e respeito a uma sociedade plural.

Infelizmente, alguns países da América Latina, a exemplo do Brasil, parecem alheios a este novo constitucionalismo que invade o continente, repensando o significado e função de povo e chamando-o a exercer sua função como tal. A mídia tem abafado notícias desse cunho, em uma tentativa de nos fechar em uma concepção ainda muito liberal de Estado Social Democrático de Direito. Somente com a retomada de poder pelo seu titular originário, a partir da promoção da democracia participativa, a começar pela popularização dos meios de comunicação, é que podemos resgatar conceitos tais como cidadania e espaço público, pilares da democracia que se encontram em ruínas, sobrevivendo de aparências e sendo engolidos pela crise da democracia representativa.

Só se pode falar em Estado Democrático de Direito quando fizermos parte de uma sociedade livre e plural, onde haja espaço para expressar tudo que isto implica. Neste sentido, dispõe Hesse (2009, p. 52)

\footnotetext{
A liberdade do indivíduo só se pode dar numa comunidade livre, e vice-versa; essa liberdade pressupõe seres humanos e cidadãos com capacidade e vontade para decidir por si mesmos, sobre seus próprios assuntos e para colaborar responsavelmente na vida da sociedade publicamente constituída como comunidade.
}

O espaço público deve ser entendido como um mecanismo de possibilidades múltiplas, garantindo assim a concretização dos sistemas participativos da democracia, posto que assegure a expressão política dos mais diversos segmentos, em um verdadeiro exercício da conscientização cidadã. Deve-se ser pensado ainda no papel das entidades locais que, por estarem mais próximas ao sujeito, fazem com que a cidadania e, por conseguinte, os pilares da democracia, se fortaleçam com maior velocidade, diferentemente do que ocorre com o conteúdo veiculado pela opinião pública, que, aliás, de pública não tem nada. 


\section{CONSIDERAÇÕES FINAIS}

Uma das principais inovações da Lei de Meios do Equador diz respeito aos meios de comunicação comunitários. Segundo a Lei, o Estado deve implementar as políticas públicas necessárias para a criação e fortalecimento destes meios de comunicação alternativos. Os meios de comunicação comunitários deverão ser feitos pelo povo e para o povo, funcionando, assim, como mecanismo para promover a pluralidade, a diversidade, o multiculturalismo.

Outra inovação concernente aos meios comunitários está relacionada aos espectros de rádio, no qual 34\% do total do país serão destinados às rádios comunitárias. O objetivo da Lei é alcançar que as frequências do espectro de rádio, bem como da televisão do país, sejam distribuídas uniformemente em três partes, reservando 33\% dessas frequências para operação pública, 33\% para a operação dos meios de comunicação privados, e 34\% para funcionamento dos meios de comunicação comunitários. Apesar da Lei de Meios fazer menção à distribuição equitativa também da televisão, no artigo damos ênfase apenas à comunicação comunitária a partir do rádio, quais seja devido a sua facilidade de implementação, no que concerne à produção de conteúdo e facilidade de dissipação do seu espectro magnético por todo o território nacional.

Também há inovações na administração e funcionamento dos meios comunitários, tais como a promoção de crédito preferencial para a criação destes meios e compra de equipamento; isenções fiscais para a importação de equipamentos para funcionamento de rádio comunitária e da televisão; acesso à formação para a gestão comunicativa, administrativa e técnica da mídia comunitária.

Destaca-se a ação afirmativa do Estado em promover a liberdade de expressão, ou seja, este direito é visto também como um direito de participação, que requer uma prestação positiva do Estado, por meio de ações afirmativas; neste caso, a promoção e consolidação das rádios comunitárias, como forma de mobilização social e efetivação da cidadania. A partir da utilização dos pressupostos do novo constitucionalismo latino-americano, a exemplo de uma série inédita de direitos coletivos, como os direitos do Buen Vivir, e do alargamento da democracia participativa, são colocados em prática novos modelos para a democratização da dos meios de comunicação e superação da crise da democracia representativa no atual Estado Democrático Social de Direito. 


\section{REFERÊNCIAS}

BAHIA, Lílian Mourão. Rádios comunitárias: mobilização social e cidadania na reconfiguração da esfera pública. Coleção Comunicação e Mobilização Social. Belo Horizonte: Autêntica Editora, 2008.

BONAVIDES, Paulo. Teoria Constitucional da Democracia Participativa: Por um direito constitucional de luta e resistência. Por uma nova hermenêutica. Por uma repolitização da legitimidade. São Paulo: Malheiros Editores, 2001.

BRAGATO, Fernanda Frizzo. O que há de novo no constitucionalismo latinoamericano: reflexões sobre o giro descolonial. In: STRECK, Lênio Luiz; GOMES, Ana Cecília de Barros; TEIXEIRA, João Paulo Allain (Orgs.). Descolonialidade e Constitucionalismo na América Latina. Belo Horizonte: Arraes Editores, 2015.

; CASTILHO, Natália Martinuzzi. A importância do póscolonialismo e dos estudos descoloniais na análise do novo constitucionalismo latinoamericano. In: BELLO, Enzo; VAL, Eduardo Manuel (Orgs.). O pensamento pós e descolonial no novo constitucionalismo latino-americano [recurso eletrônico]. Caxias do Sul: Educs, 2014. P. 11-25.

BRANDÃO, Pedro. O novo constitucionalismo pluralista latino-americano. Rio de Janeiro: Lumen Juris, 2015.

BRASIL. Constituição da República Federativa do Brasil de 1988. Disponível em: http://www.planalto.gov.br/ccivil_03/constituicao/ConstituicaoCompilado.htm. Acesso em: 10 nov. 2014.

BUCCI, Eugênio. Os sentidos do Rádio. In: FILHO, André Barbosa; PIOVESAN, Ângelo; BENETON, Rosana (Orgs.). Rádio. Sintonia do Futuro. São Paulo: Paulinas, 2004. 
EQUADOR. Constituición de la República del Equador. Disponível em: http://www.stf.jus.br/repositorio/cms/portalStfInternacional/newsletterPortalInternacionalFoc o/anexo/ConstituicaodoEquador.pdf. Acesso em: 10 nov. 2014.

- Ley orgánica de comunicación Equador. Disponível em: http://ecuador.indymedia.org/media/2012/02/38137.pdf. Acesso em: 10 nov. 2014.

FAJARDO, Raquel. El horizonte del constitucionalismo pluralista: del multiculturalismo a la descolonizacíon. In: GARAVITO, C. R. El derecho em América Latina: um mapa para el pensamento jurídico del siglo XXI. Buenos Aires: Siglo Ventuino Editores, 2011.

GIMENEZ, Gilberto. Notas para uma teoria da comunicação popular. Cadernos CEAS. Salvador: CEAS, n. 6, maio-jun,1979. P. 57-61.

HESSE, Konrad. Temas Fundamentais do Direito Constitucional. Trad. Carlos dos Santos Almeida. São Paulo: Saraiva, 2009.

MACHADO, Jónatas. Liberdade de Expressão: Dimensões Constitucionais da Esfera Pública no Sistema Social. Coimbra: Coimbra Editora, 2002.

MENDES, Gilmar Ferreira; BRANCO, Paulo Gustavo Gonet. Curso de Direito Constitucional. 4 ed. São Paulo: Saraiva, 2009

NEVES, Marcelo. Estado Democrático de Direito: o modelo. In: Entre Têmis e Leviatã: uma relação difícil. 3 ed. Porto Alegre: Livraria do Advogado, 2012. p. 123-196.

PERUZZO, Cicília Maria Krohling. "Rádio Comunitária, Educomunicação e Desenvolvimento". In: PAIVA, Raquel (Org.). O Retorno da Comunidade: os novos caminhos do social. Rio de Janeiro: Mauad X, 2007.

ROMEO, Francisco Palacios. La reinvidicación de la polis: Crisis de la representación y nuevas estructuras constitucionales de deliberación y participación in Latinoamérica. In: 
STORINI, Claudia (Org.). Materiales sobre neoconstitucionalismo y nuevo constitucionalismo latinoamericano. Cizur Menor/Navarra/Espanha: Aranzadi, 2014. p. 147221.

SANTAMARÍA, Ramiro Ávila. El neoconstitucionalismo transformador: el Estado y el derecho en la Constitución de 2008. Quito, 2011. Disponível em: http://www.rosalux.org.ec/attachments/article/239/neoconstitucionalismo.pdf. Acesso em: 10 nov. 2014.

WOLKMER, Antonio Carlos. Pluralismo e Crítica do Constitucionalismo na América Latina. In: Anais do IX Simpósio Nacional de Direito Constitucional. Curitiba: Academia

Brasileira de Direito Constitucional, 2010. P. 143-155. Disponível em: http://www.abdconst.com.br/revista3/antoniowolkmer.pdf. Acesso em: 10 nov. 2014. 